\title{
O PAPEL DOS PCN’S: O ENSINO DE HISTÓRIA NO BRASIL
}

\author{
Henrique R. Silva, Jackeline C. A. Oliveira, Alba R. A. Arana
}

Universidade do Oeste Paulista - UNOESTE, Licenciatura em História, Presidente Prudente, SP. E-mail: henrique.agroecologia@hotmail.com

\section{RESUMO}

O ensino de História deve desenvolver a reflexão do educando despertando a compreensão da história do mundo e da sociedade na qual ele esta inserido. Desta forma, este artigo teve como objetivo verificar os PCNs e suas propostas para o ensino de história, apresentando as linguagens alternativas para o ensino de história presentes nos PCNs. Analisamos e discutimos a realidade do ensino de Historia, na Escola Estadual do município de Sandovalina - SP. A pesquisa foi bibliográfica e de campo com abordagem qualitativa, a técnica utilizado foi a entrevista. Sabemos que a escola é um ambiente de construção de aprendizagem, no qual o procedimento de ensino e aprendizagem deve propiciar ao educando a desenvolver seu pensamento, e nesse procedimento cabe ao professor se interrogar de que forma o educando irá compreender aquilo que o educador apreendeu na universidade.

Palavras-chave: Ensino de História, Metodologias, Educação, Aprendizagem.

\section{THE ROLE OF NCP'S: THE HISTORY TEACHING IN BRAZIL}

\section{ABSTRACT}

The teaching of history must develop the student's reflection awakening understanding of world history and the society in which it is inserted. Thus, this study aimed to verify the NCPs and their proposals for the teaching of history, presenting the alternative languages for teaching history present in the PCNs. We analyze and discuss the reality of history teaching in state school in the city of Sandovalina - SP. The research was bibliographical and field with a qualitative approach, the technique used was the interview. We know that the school is a learning construction environment in which teaching and learning procedure should provide the students to develop their thinking, and this procedure is up to the teacher to question how the student will understand what the teacher seized in university.

Keywords: History teaching, methodologies, Education, Learning.

\section{INTRODUÇÃO}

O artigo faz uma reflexão sobre a importância do ensino de História na escola estadual, enfocando a metodologia do ensino apontando a importância de rever os objetivos do ensino da disciplina e propondo mudanças metodológicas na sua prática, visando criar condições de superação do ensino tradicional.

A partir deste estudo, compreendemos a pratica dos professores e suas influencias no desempenho da função docente. A pesquisa partiu dos seguintes questionamentos: Como tornar significativo o ensino de História? O ensino de História deve desenvolver a reflexão do educando? Como a escola pode torna-se num ambiente de construção de aprendizagem reflexiva e crítica? Qual o papel do professor?

A pesquisa em questão teve como objetivo verificar os PCNs e suas propostas para o ensino de história, e também apresentar as linguagens alternativas para o ensino de história presentes nos PCNs. Analisamos e discutimos a realidade do ensino de Historia na Escola Estadual no município de Sandovalina - SP.

\section{METODOLOGIA}

A metodologia utilizada nesta pesquisa foi baseada na investigação qualitativa, utilizando-se de levantamento bibliográfico, de pesquisa documental fundamentada na leitura, análise e reflexões das ideias expostas pelos 
autores que respaldam o trabalho, assim assegurando as condições necessárias para alcançar os objetivos propostos no projeto de pesquisa. Para a análise sistemática dos resultados obtidos, foi necessário um diálogo entre as literaturas selecionadas na revisão bibliográfica, os sites consultados e as informações coletadas através de entrevistas que foram realizadas junto aos professores da Escola Estadual no município de Sandovalina - SP.

A partir da teoria apreendida e dos conceitos elaborados, a investigação passou para a fase de pesquisa documental. A análise documental "pode-se constituir numa técnica valiosa de abordagem de dados qualitativos, seja complementando as informações obtidas por outras técnicas, seja desvelando aspectos novos de um tema ou problema" (LÜDKE ; ANDRÉ, 1986, p. 38).

A coleta de dados foi realizada no mês de maio de 2016 junto aos professores da Escola Estadual do Município de Sandovalina - SP. As técnicas utilizadas foram: observações assistemáticas e entrevistas semi-estruturadas com os professores da escola.

\section{OS PCNS E SUAS PROPOSTAS PARA O ENSINO DE HISTÓRIA.}

Os Parâmetros Curriculares Nacionais (PCNs) apresentam suas propostas para o ensino de história e procuram traçar paralelos entre alguns elementos desse contexto e o seu conteúdo. O objetivo é demonstrar que o PCNs, constitui um fator de organização do currículo do ensino, e, portanto consiste um aspecto importante de saberes histórico.

Nesse cenário das reformas educacionais brasileiras dos anos 1990, o MEC divulgou os Parâmetros Curriculares Nacionais (PCNs) de 1a a 4ạ séries, em 1997; de 5a a 8a séries, em 1998, e de Ensino Médio, em 1999, acrescentando o PCN + (Orientações Educacionais Complementares aos Parâmetros Curriculares Nacionais), de 2002.

0 processo de preparação dos $\mathrm{PCNs}$ passou por um estudo efetuado, a requisito do MEC, pela Fundação Carlos Chagas, a respeito de propostas curriculares de estados e municípios brasileiros. Com base desses estudos, elaborouse uma "versão preliminar" e colocou-se um debate nacional, do qual se envolveram professores universitários, representantes de secretarias estaduais e municipais de educação, além de outros educadores e pesquisadores.
Os PCNs para o ensino médio apontam uma observação aprofundada sobre as temáticas e conceitos que já se mostraram em outros anos, apesar disso têm como objetivo central a preparação para a cidadania, ou seja, há uma responsabilidade em organizar a formação da cidadania com o conhecimento e domínio dos conceitos históricos. Não o objetivo em profissionalizar o aluno, no entanto é necessário que eles possuam conhecimento sobre os fatos e acontecimentos históricos. Um dos propósitos é impor o trabalho pedagógico com propostas de leitura de bibliografia especifica sobre os temas estudados.

A fim de que o processo se forme, é necessário que a história discuta com as demais disciplinas, também com as de extras áreas, a fim de consolidar e aprofundar o que já foi estudado no Ensino Fundamental.

A abordagem que decorre nos Parâmetros para o ensino de história recomenda claramente que a escola deverá se submeter aos temas da História Nova, principalmente aqueles relacionados ao cotidiano, realizando as articulações entre a micro e a macro história, buscando nas peculiaridades dos resultados os desenvolvimentos necessárias para as percepções do processo históricos. Dentro desta estrutura teórico-metodológica, a interdisciplinaridade é fundamental, se constituindo uma ferramenta maior para a compreensão do tempo presente, do mundo social e de suas representações.

$$
\text { Baseando-se dos problemas }
$$

contemporâneos, cabe ao professor escolher as competências estabelecidas pelos PCNs que deve aprimorar, para poder formar os conteúdos que sejam significantes para o educando. Desse modo a seleção acarretará, necessariamente, em apoderação de posições teórico-metodológicas claras e objetivas, para que a constituição dos objetos seja as melhores para o entendimento da contemporaneidade.

\section{DISCUSSÃO}

As propostas curriculares para o ensino de História no ensino médio estão centradas no desenvolvimento da interdisciplinaridade, transversalidade e nos currículo por competências, também foi direcionado para promover o desenvolvimento da cidadania e para a capacitação para os usos das tecnologias. Os eixos temáticos são propostos para buscar os conhecimentos e desenvolver habilidades, 
representação e comunicação, investigação e compreensão e contextualização sociocultural.

Para colocar em prática essas propostas curriculares do ensino de História é relevante que o educador considere novas possibilidades de trabalho pedagógico, em que os educandos sejam motivados a construir e a reconstruir conceitos, vivenciando momentos em que possam pesquisar coletar informações em diversas fontes, discutir, refletir e relacionar-se de maneira a colaborar para o desenvolvimento de sujeitos ativos e criativos.

O método de planejamento de uma
disciplina colabora para seu bom desenvolvimento, pois torna seus conteúdos mais contextualizados e sua metodologia mais criativa, porém ao colocar em prática o que foi planejado nos deparamos com varias dificuldades e visualizamos outras possibilidades de ensino, o que nos leva a reconhecer a relevância de avaliarmos frequentemente, nossas práticas pedagógicas e refletirmos em relação a essas experiências educativas.

Segundo os PCN,s:

A organização de conteúdos por temas requer cuidados específicos com a escolha dos métodos. $O$ estudo de temas articulado à apropriação de conceitos ocorre por intermédio de métodos oriundos das investigações históricas, desenvolvendo a capacidade de extrair informações das diversas fontes documentais tais como textos escritos, iconográficos, musicais. A apropriação do método da pesquisa historiográfica, reelaborada em situações pedagógicas, possibilita interpretar documentos e estabelecer relações e comparações entre problemáticas atuais e de outros tempos. Torna-se necessário escolher métodos que auxiliem a capacidade de relativizar as próprias ações e as de outras pessoas no tempo e no espaço. (BRASIL. Secretaria de
Educação

Fundamental, 1999, p. 305).

É preciso criar metodologia para trabalhar em sala de aula, a primeira coisa que os educadores têm que fazer é mudar a visão que o educando têm sobre a documentação, mostrando para ele como é feita a documentação, que são produtos construídos e pertencentes a uma determinada historia, mostrar a subjetividade da documentação.

$O$ educador pesquisador consegue trazer para as suas aulas, um toque de estímulo que faz surgir nos educando, anseios e necessidades de aprender. A inquietude que a pesquisa desperta no pesquisador é a mesma existente no educador pesquisador, que por sua vez, transmite-a para os seus educando, fazendo com que eles tomem gosto pela disciplina de História. Como escreveu Jacques Le Goff:

documento não é inócuo.

É antes de mais nada o resultado de uma montagem, consciente ou inconsciente, da história, da época, da sociedade que o produziram, mas também das épocas sucessivas durante as quais continuou a viver, talvez esquecido, durante as quais continuou a ser manipulado, ainda que pelo silencio. $O$ documento é uma coisa que fica, que dura, e o testemunho, o ensinamento (para evocar a etimologia) que ele traz devem ser em primeiro lugar analisados desmistificando Ihe 0 seu significado aparente (LE GOFF, 2003, p. 537-538).

De acordo com Schmidt (2012) e de outros educadores que lidam com o ensino de História, existe uma grande preocupação em fazer com que os alunos construam um vocabulário histórico, que seja facilmente assimilável e possa ser utilizado em diferentes situações reais de sua vida. Outra preocupação que surgiu, mas não menos importante, foi à importância dos alunos terem possibilidades de realizar suas próprias construções sobre os fenômenos e objetos do mundo social, não sendo 
apenas meros receptores passivos das informações do professor. Eles devem ter competências para formularem suas próprias hipóteses e interrogações acerca do mundo que interagem.

Se o trabalho com a construção de conceitos históricos deve integrar o processo ensino-aprendizagem de História, é necessário ter cuidado para não transformar este objetivo no uso excessivo de termos técnicos ou na imposição de definições abstratas e memorizações formais de palavras e do seu conceito. Aprender conceitos não significa acumular definições ou saberes formais, mas elaborar uma grade que auxilie o educando na sua compreensão e explicação da realidade social. No ensino de História, a construção de grades conceituais pelo educando pode facilitar a compreensão do mundo onde vive.

Segundo, Schmidt:

Um trabalho sistematizado com os conceitos históricos pode contribuir para que alunos e professores realizem uma leitura mais reflexiva e crítica dos documentos e conteúdos históricos. Este trabalho não deve ser feito de maneira fragmentada e isolada, do tipo atividades no final de capítulos de livros ou unidades, mas de forma orgânica e sistemática no decorrer do processo de ensino-aprendizagem, integrado às atividades cotidianas da sala de aula. Ademais, o trabalho com conceitos históricos deve integrar a vivência cotidiana da transposição didática do conhecimento de referência em saber histórico escolar. (SCHMIDT, 2012, p.163)

Uma das formas de motivarmos os educando e educadores sobre a importância do ensino de história se baseia em atividades diferenciadas como construção de projetos interdisciplinares, de desenvolver pesquisa de campo, dessa maneira cria-se a oportunidade para que o educando construa seu conhecimento e se tornem sujeitos da história, e o educador seja o mediador dessas aprendizagens.

É importante o educador saber que: "quanto mais o aluno sentir a história como algo próximo dele, mais terá vontade de interagir com ela, não como uma coisa externa, distante, mas como uma prática que ele se sentirá qualificado e inclinado a exercer" (KARNAL, 2008, p. 28).

\section{RESULTADOS DA PESQUISA}

Foi realizada a pesquisa de campo, com observações e entrevistas semiestruturada com os professores da escola, com os seguintes resultados.

Segundo o entrevistado a motivação para a carreira partiu pelo respeito, gostava realmente da profissão. Os contextos históricos vividos pelos educadores, em diversos períodos, revelam circunstâncias das lutas pela sobrevivência e dos embates políticos cotidianos. Primeiramente cursou a Licenciatura na Faculdade de Ciências, Letras e Educação de Presidente Prudente (UNOESTE) S.P, licenciando-se em História. Começou a lecionar como professor em 2008, na cidade de Estrela do Norte no Estado de SP.

Os relatos dos acontecimentos partilhados, obstáculos, tristezas e alegrias mostram como determinadas experiências históricas são estimuladoras do progresso pessoal e profissional de cada um dos sujeitos conforme suas palavras: "Ao assumir as aulas, na primeira semana já deu vontade de desistir, pois não era o que esperava, mas foi com a persistência de alguns professores e diretores que me auxiliaram a continuar..."

O educador carrega em si uma simpatia especial por conhecer e pesquisar possui um grau de compromisso diferente para com seus educando, usa novas técnicas e práticas de ensino. Competência, compreensão, incumbência marcam o itinerário desse profissional que luta por um ensino satisfatório. Porém, defronta-se com graves dificuldades de ordem institucional no seu cotidiano.

Quando perguntado sobre que tipo de atividades que ele costuma usar para aprimorar o entendimento de seus alunos assim diz: "[...] Costumo trabalhar com os alunos varias ferramentas para aprendizagem como vídeos, documentários, livro didático, caderno proposto pelo governo, leituras e interpretações [...] se tem mais ferramentas que podemos desfrutar mais a escola não disponibiliza, o acesso é muito burocrático." 
Em uma das perguntas sobre a auto avaliação, o professor nos responde "Nós professores de História se vemos de uma forma ou de outra trabalhando em duas ou mais escolas, pois as aulas estão diminuindo, o governo fechando sala de aula e com isso o professor fica com muito mais tarefa $e$ a valorização não se tem. Outro problema que o professor de História vem enfrentando são as disciplinas na qual vêm conteúdos contemplando o mesmo conteúdo. Ela traz outra visão dentro da própria escola, os próprios colegas de trabalho, acha que História, Sociologia e Filosofia são disciplinas qualquer $e$ que as disciplinas importantes são apenas as de Português $e$ Matemática."

A fala nos mostra que em vários sistemas de educação escolar, tanto as criticas ao fracasso ou insucesso, quanto à fé e as expectativas de mudanças no sistema estão concentradas, especialmente, no professor e na sua formação. No Brasil, a formação do professor aparece tanto como "bode expiatório", uma das principais causas do fracasso educacional brasileiro, quanto como "panacéia", formula milagrosa capaz de mudar as práticas em nossas escolas, melhorando a qualidade do ensino. (FONSECA, 2015. p.72).

\section{CONCLUSÃO}

Compreendemos que apesar de grandes modificações no objetivo da educação ao longo da história, percebe-se que 0 papel desempenhado pelo educador e também 0 ensino tiveram grandes transformações. Embora a sociedade em geral passe por amplas reestruturas, o professor de História continua praticamente desempenhando da mesma forma sua ofício.

Em suma, verificou-se que a construção de conhecimentos significativos para a formação consistente dos educando precisam ser aprimoradas, novas práticas precisam ser efetivadas para um processo realmente dinâmico, multidimensional e crítico-reflexivo do ensino. Bem diferente de uma memorização consciente, em que é proposto para o aluno buscar e construir informações e que tem no professor um mediador, estimulando os alunos a produzirem e fazerem suas descobertas históricas. As práticas educativas ainda necessitam de um aperfeiçoamento mais significativo e renovador, que transforme o ensino de história em algo prazeroso, que tenha sentido e função na formação de alunos, na contribuição de seres reflexivos e críticos sobre sua função social.

É preciso ressaltar que muitos percursos históricos podem ser realizados, muitas histórias podem ser construídas, pois é necessário que os educadores contribuam no sentido de possibilitar nos seus educandos uma nova forma de ler e estar no mundo, tanto enquanto sujeito participante dele, como um cidadão que, ao se posicionar sobre sua realidade, seja capaz de compreendê-la e de transformá-la.

\section{REFERENCIAS}

BRASIL. Secretaria de Educação Fundamental. Parâmetros curriculares nacionais: ensino médio. Brasília: Ministério da Educação, 1999. LE GOFF, Jacques. História e memória. 5. ed. Campinas, SP: Ed. da Unicamp, 2003, p. 525-541. LÜDKE, Menga ; ANDRÉ, Marli E. D. A. Pesquisa em educação: abordagens qualitativas. São Paulo: Pedagógica e Universitária, 1986. KARNAL, Leandro. História na sala de aula: conceitos, práticas e propostas. [S.I.]: Contexto, 2003.

SCHMIDT, Maria Auxiliadora. Construindo conceitos no ensino de História: a captura lógica da realidade social. História \& Ensino, v. 5, p.147164, 2012.

Recebido para publicação em 19/08/2016

Revisado em 24/08/2016

Aceito em 26/08/2016 